\title{
Utilization of combined remote sensing techniques to detect environmental variables influencing malaria vector densities in rural West Africa
}

Peter Dambach ${ }^{1 *}$, Vanessa Machault ${ }^{2}$, Jean-Pierre Lacaux ${ }^{2}$, Cécile Vignolles ${ }^{3}$, Ali Sié ${ }^{4}$ and Rainer Sauerborn ${ }^{5,1}$

\begin{abstract}
Introduction: The use of remote sensing has found its way into the field of epidemiology within the last decades. With the increased sensor resolution of recent and future satellites new possibilities emerge for high resolution risk modeling and risk mapping.

Methods: A SPOT 5 satellite image, taken during the rainy season 2009 was used for calculating indices by combining the image's spectral bands. Besides the widely used Normalized Difference Vegetation Index (NDVI) other indices were tested for significant correlation against field observations. Multiple steps, including the detection of surface water, its breeding appropriateness for Anopheles and modeling of vector imagines abundance, were performed. Data collection on larvae, adult vectors and geographic parameters in the field, was amended by using remote sensing techniques to gather data on altitude (Digital Elevation Model = DEM), precipitation (Tropical Rainfall Measurement Mission = TRMM), land surface temperatures (LST).

Results: The DEM derived altitude as well as indices calculations combining the satellite's spectral bands (NDTI = Normalized Difference Turbidity Index, NDWI Mac Feeters = Normalized Difference Water Index) turned out to be reliable indicators for surface water in the local geographic setting. While Anopheles larvae abundance in habitats is driven by multiple, interconnected factors - amongst which the NDVI - and precipitation events, the presence of vector imagines was found to be correlated negatively to remotely sensed LST and positively to the cumulated amount of rainfall in the preceding 15 days and to the Normalized Difference Pond Index (NDPI) within the $500 \mathrm{~m}$ buffer zone around capture points.
\end{abstract}

Conclusions: Remotely sensed geographical and meteorological factors, including precipitations, temperature, as well as vegetation, humidity and land cover indicators could be used as explanatory variables for surface water presence, larval development and imagines densities. This modeling approach based on remotely sensed information is potentially useful for counter measures that are putting on at the environmental side, namely vector larvae control via larviciding and water body reforming.

Keywords: Remote sensing, High spatial resolution, SPOT 5 satellite, Malaria, Rural West Africa, Burkina Faso, Geographic information system, Digital elevation model, MODIS, TRMM

\footnotetext{
* Correspondence: peter.dambach@web.de

'Institute of Public Health, University of Heidelberg, Heidelberg, Germany

Full list of author information is available at the end of the article
} 


\section{Background}

Malaria is still widespread in Western Africa and results in severe illness, death and hence in economic damage to households and national economy. The desirable overall use of countermeasures and strategies against malaria and its vector, such as use of bed nets, larviciding, habitat reduction etc., is still below the needed amount for showing a remarkable impact.

During the past two decades, remotely sensed data has been used to describe and predict geographical and temporal patterns in vector-borne disease transmission and disease prevalence [1-3]. The basic idea behind the remotely sensed assessment of malaria determinants is to define environmental parameters that can be used to identify areas with increased risk. One of the main goals of this approach could be the detection of breeding habitats or the mapping of vector densities through remote sensing techniques, while some other studies linked climate and environmental parameters directly to malaria prevalence [2,4-6]. The suitability of habitats for mosquito larvae breeding is dependent on the presence and distribution of specific environmental variables (i.e., surface water, water related vegetation and distribution and amount of precipitation) [7]. Studies mapping Anopheles mosquito breeding habitats, transmission, or disease have been made in Africa [4,8-10] South and Central America [11-14] and Asia [15,16]. Reliable information about vector density and malaria transmission risk is essential for understanding variations in disease epidemiology and targeting intervention programs, which are useful tools at the continental and national scales, but are less appropriate in a context of localscale variations in disease patterns that often vary within a few kilometers distance. Nevertheless, high local variation in malaria epidemiology is particularly common in the Sahel region of Africa, where malaria is characterized by very focal and seasonal transmission [10,17-19].

In this paper we argue that, for the understanding of local malaria ecology on a high resolution scale, an integrated view on multiple influencing factors is helpful, comprising the following objectives:

1. To detect surface water and water-related land cover within the survey region.

2. To assign appropriateness for vector larvae breeding to those land cover types.

3. To investigate the influence of environmental and meteorological variables on larvae and adult vector abundance.

4. To predict the adult Anopheles densities in villages using those variables as well as the surrounding densities of larvae.

5. To validate the predicted vectorial risk using ground captured Anopheles mosquitoes.

\section{Methods}

The study site is located in the North-Western part of Burkina Faso in the Kossi district (Figure 1). The study region shows altitudes around $200 \mathrm{~m}$ with increasing elevations towards the West. The mean precipitation for

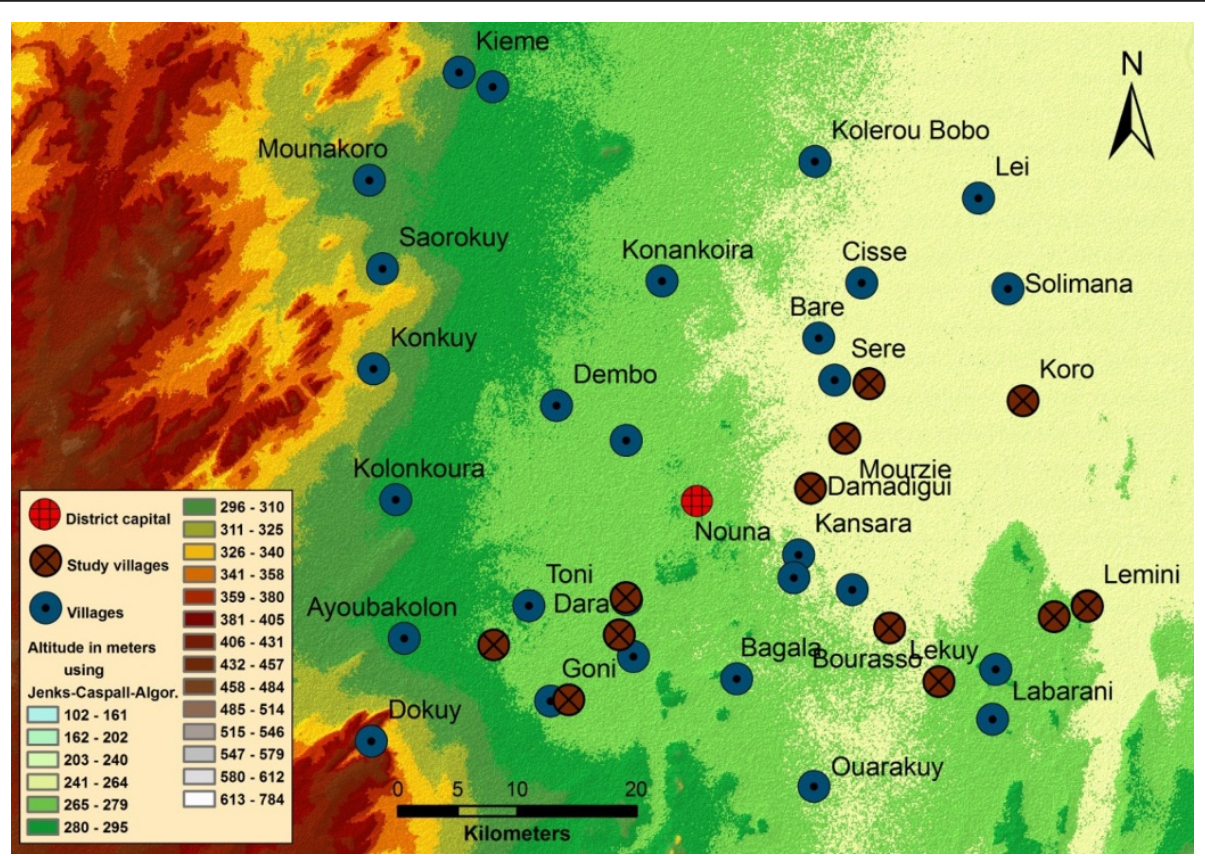

Figure 1 Digital Elevation Model of the survey region [20]. Classes were built using natural breaks (Jenks-Caspall-algorithm). The villages and the study villages are presented respectively in blue and dark red. 
Nouna has been $817 \mathrm{~mm}$ per year over a period of the last ten years, with about $90 \%$ of annual rainfall during the rainy season (June to September). The monthly maxima during the rainy season can reach up to 350 $\mathrm{mm}$. The yearly average temperature of Nouna is $27.8^{\circ}$ C. The North Western savannah regions of Burkina Faso are a malaria holo-endemic area with a marked seasonality. The study took place between July and September 2009, in 12 villages of the region (amongst which 10 were covered by the SPOT- 5 satellite scene).

Satellite images from the SPOT-5 (Satellite Pour l'Observation de la Terre) were programmed and acquired for October $12^{\text {th }} 2009$, during the rainy season. Data included three spectral bands at $2.5 \mathrm{~m}$ spatial resolution (green, red and near infrared - NIR). One band for the short wave infrared (SWIR) was also available at $10 \mathrm{~m}$ spatial resolution. The three first bands were upscaled to $10 \mathrm{~m}$ and stacked with the fourth $10 \mathrm{~m}$ band. All images were level 3 pre-processed (orthoimages), with map projection UTM zone $30 \mathrm{~N}$, and datum WGS 84. In the center of the satellite scene, which was $60 \times 60 \mathrm{~km}$, the district capital Nouna is located at $12^{\circ} 44^{\prime} \mathrm{N} ; 3^{\circ} 51^{\prime} \mathrm{W}$.

A Digital Elevation Model (DEM) at $90 \mathrm{~m}$ spatial resolution was available from the Shuttle Radar Topography Mission (SRTM version 4.1) [20,21]. It was resampled at $10 \mathrm{~m}$ spatial resolution.

Weekly day and night Land Surface Temperatures (LST) were extracted from MODIS (Moderate Imaging Spectroradiometer) images at $1 \mathrm{~km}$ spatial resolution for the full duration of the field work. The freely available MODIS Reprojection Tool [22] was used to extract LST values and to project the resulting images. The weekly LSTs were averaged for the survey region.

The TRMM (Tropical Rainfall Measurement Mission) daily data at $25 \mathrm{~km}$ spatial resolution were downloaded for the duration of the survey period including an additional month, for calculating the cumulated precipitations within different time lags before larvae and adult mosquito captures respectively.

The data analysis was based on the conceptual approach of tele-epidemiology developed by CNES, the French Space Agency [23]i.e. i- assembling and analyzing multidisciplinary in-situ datasets to identify the main biological and physical mechanisms at stake in order to highlight the main factors implied in the diseases spatial and temporal distribution; ii- remote-sensing monitoring of environment linking the disease with the parameters previously identified with the aim to obtain well adapted products from space; iii- modeling to generate predictive environmental risk maps (Figure 2). This methodology has been previously applied successfully for the Rift Valley Fever in North Senegal [24,25] and for urban malaria in Dakar [26,27]. The basic requirement for malaria to occur is the presence of the vector, Anopheles. The

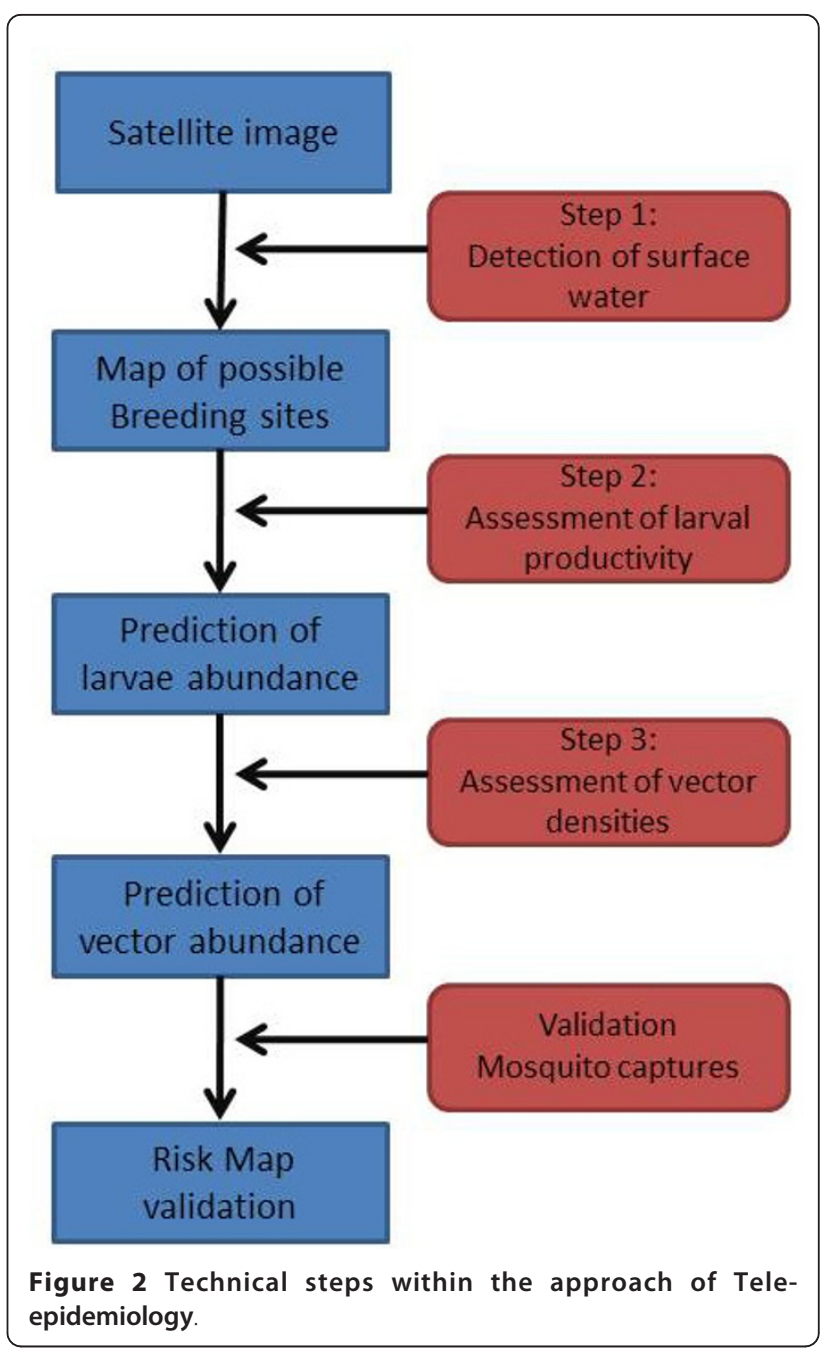

abundance of larvae and adults is directly linked to the presence, distribution and persistence of water bodies (puddles, ponds...). Based on this knowledge, the first step of this present study was the detection of surface water (hereafter called step 1). The second part (hereafter called step 2) analyzed the environmental parameters in and around the water collections, that could be related to larvae presence and abundance, and the third step (hereafter called step 3) aimed at identifying the relationships between the predicted larval production, the environmental and meteorological information with the ground recorded Anopheles densities, representing a risk indicator for human population.

A Geographic Information System was built in ArcGIS 9.3, containing all remotely sensed and field data. All environmental information was extracted at $10 \mathrm{~m}$ pixel level or at village level and transferred into Stata 12 (Stata Corporation, College Station, Texas) for statistical modeling. Multiple indices combining different spectral bands were calculated from the SPOT-5 images using 
Table 1 Different indices combining different spectral bands were tested for statistical association with presence of surface water in step 1 and for correlation with larvae abundance in step 2

\begin{tabular}{lc}
\hline Index & Calculation \\
\hline NDVI [29] & $\frac{N I R-\text { red }}{N I R+\text { red }}$ \\
Sormalized Difference Vegetation Index & NIR - red \\
\cline { 2 - 2 } Soil Adjusted Vegetation Index & NIR + red \\
NDPI [24] & $\frac{\text { SWIR }- \text { green }}{\text { NWIR }+ \text { green }}$ \\
Normalized Difference Pond Index & $\frac{\text { NIR }- \text { SWIR }}{\text { NIR }+ \text { SWIR }}$ \\
NDWI Gao [31] & $\frac{\text { green }- \text { NIR }}{\text { Normalized Difference Water Index Gao }+ \text { NIR }}$ \\
NDWI Mac Feeters [32] & green - SWIR \\
Normalized Difference Water Index Mac & green + SWIR \\
MNDWI Mac Feeters [33] & $\frac{\text { red }- \text { green }}{\text { Modified NDWI Mac Feeters }}$ \\
NDTI [24] & green \\
Normalized Difference Turbidity Index &
\end{tabular}

NIR near infrared; SWIR short wave infrared

the band math functionality in ENVI 4.7 (Table 1) and tested for statistical association with the presence of surface water, Anopheles larvae and imagines abundance according to the three steps above. Land Use and Land Cover (LULC) from a supervised land cover classification were available from a previous study [28].

\section{Step 1: Mapping of surface water}

Outlines of pools and ponds (locally called "marigots"), in which continuous larvae sampling was performed, were mapped using a GPS device, and transferred to the GIS. Points, further called presence points, were

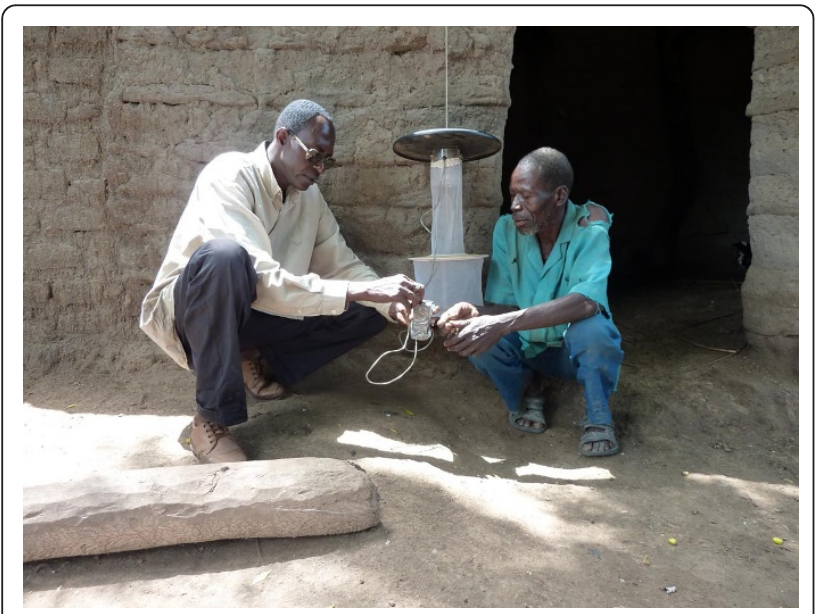

Figure 3 Installation of a mosquito light trap and giving instructions to an operator in charge for trap surveillance. generated in the center of all $10 \mathrm{~m}$ pixels that were overlaid by the shape of a water body, even for small areas. Additional points, called absence points, were randomly generated outside of the pools. A total of 482 presence points and 1978 absence points were created. The values of every indicator, as well as the LULC class and the altitude (from the DEM) were extracted at every presence and absence point. The linearity of the relationship between the outcome and each explanatory variable was assessed, except for the elevation that has been included as dichotomous variable. Logistic regressions were fitted to identify the remotely sensed environmental variables significantly associated with the presence/absence of water at each point. The inversion of the best multivariate model allowed generating a 10 $m$ resolution map of the probabilities of presence of water in the studied area.

\section{Step 2: Mapping of Anopheles larvae}

Mosquito larvae at all stages were collected daily from September $2^{\text {nd }}$ to October $23^{\text {rd }} 2009$ in the 12 study villages ( 2 villages per day with a weekly repetition (Figure $3)$ ). Within and around the villages, the follow-up concerned the most common habitats, i.e. the ponds that ranged in size from several meters to hundred meters in diameter. A standardized dipper with $200 \mathrm{ml}$ volume was used to collect larvae.

For each potential breeding site, the environment was taken into account as a mean of the remotely sensed ecological variables computed in and around the water bodies (10 $\mathrm{m}$ ring). This scale allowed taking into account the surface (e.g. surface cover as vegetation) and nearby structures (e.g. shade) on potential habitats that could have an impact on the larval presence and density. Meteorological data was tested at different temporal scales until finding the best statistical association with the larvae presence. The linearity of the relationship between the outcome and each explanatory variable was tested.

A negative binomial regression was fitted to identify those remotely sensed environmental and meteorological variables significantly associated with larval density recorded in each water body at each date. The sampling scheme implied that some correlations could exist between observations obtained in a same water collection since repeated observations could be influenced by similar environmental factors. Yet, the basic requirement for using classical statistics is the independence of observations and neglecting autocorrelations in the analysis may result in overestimation of the strength of the associations. Thus, a pond random effect was added to the models, to account for variables related to the water collection environment that could be significant determinants of the larvae abundance but would not have 
been measured in the study. The environmental indicators found to be statistically associated with the Anopheles larval density were computed and fed back into the GIS, in and around every pond predicted at step 1 of the study in order to predict larvae abundance for the whole study area.

\section{Step 3: Mapping of adult Anopheles}

In the 12 villages where the larvae collection took place, adult mosquitoes were captured using light traps. During 9 weeks from September to November 2009 villages were visited within the same time schedule as for the larvae collection, with a repetition period of 6 days. Depending on village accessibility, data was available from 5 to 7 visits. Each day, in 2 villages in the same region light traps were installed. In each village 3 places were chosen where a light trap was placed inside and outside a house respectively. Those pairs of light traps were installed in a distance of approximately $100 \mathrm{~m}$ from each other to detect possible local differences in vector abundance between different places within one village. The traps inside the houses were installed near the sleeping places if equipped with an untreated bed net, the traps outside were put beside the house within the common patio, where people stay in the evenings (Figure 3). Light traps were connected to the batteries at $6 \mathrm{pm}$ and disconnected and closed at $6 \mathrm{am}$. All mosquitoes caught in the light traps were transported to the research centers laboratory for species and gender determination.

The linearity of the relationship between the outcome and each explanatory variable was verified. Then, a negative binomial regression with a village random effect was fitted to predict the density of adult Anopheles caught in each village (mean of all the traps) at each date of the ground work using remotely sensed environmental and meteorological predictive variables, as well as larval densities predicted in step 2. As the sampling scheme implied that some correlations could exist between observations from the same village, a random effect was added at the village level.

To predict the adult Anopheles densities in non-surveyed villages for every day of the study period, the environmental indicators that were found to be statistically associated with the adult Anopheles density were computed in buffers of $500 \mathrm{~m}$ around the villages, in accordance with the flight range of emerged mosquitoes from their breeding habitat [34-36].

\section{Results}

\section{Step 1: Mapping of surface water}

A description of the distribution of the remotely-sensed variables used at this step is presented in Table 2. Significant correlations were found in uni- and multivariate analysis between the NDWI Mac Feeters (Normalized Difference Water Index), the NDTI (Normalized Difference Turbidity Index) and the DEM (Digital Elevation Model) amongst 2,460 observations of the presence/ absence of ponds at $10 \mathrm{~m}$ pixel level (Table 3 ). The DEM shows differences in altitude between study villages of about $100 \mathrm{~m}$ (Figure 1). Even if the contrast of mean elevation between presence and absence points was low, a significant association was highlighted between a low elevation and an increased probability for the presence of ponds. While the NDWI Mac Feeters was positively correlated with the presence of environmental surface water, the NDTI was found to be a protective factor.

Predictions of the probability for the presence of ponds allowed to calculate the area under the ROC (receiver operating characteristic) curve at 0.99 (95\% confidence interval: $0.99-1.00)$. The ROC curve is a visualization of the sensitivity, or true positive rate, vs. false positive rate for a binary classifier system whose discrimination threshold is varied. The inversion of the model and the extrapolation for the whole study area allowed generating a map of the probability of presence of water bodies. The application of a cut-off value on those probabilities provided a raster map of the presence/absence of water at $10 \mathrm{~m}$ spatial resolution. The filtering (closing filter) and vectorization allowed transforming those maps into maps of ponds. A total of 4,600 water bodies were detected which sizes ranged from 100 to about $5,000 \mathrm{~m}^{2}$.

Table 2 Description of the quantitative remotely-sensed explicative variables associated with the presence of ponds

\begin{tabular}{llrr}
\hline Variable & & $\begin{array}{r}\text { Water } \\
\text { present }\end{array}$ & Water absent \\
\hline & $\mathbf{n}$ observations $=$ & $\mathbf{n}=\mathbf{4 8 2}$ & $\mathbf{n}=1 \mathbf{1 9 7 8}$ \\
\hline NDTI & Range & $-0.25 ;-0.01$ & $-0.26 ; 0.05$ \\
& Mean and 95\% Cl & $-0.14[-0.15 ;$ & $-0.10[-0.10 ;$ \\
& & $-0.15]$ & $-0.09]$ \\
& 25-50-75 percentiles & $-0.20 ;-0.13 ;$ & $-0.13 ;-0.09 ;$ \\
& & -0.10 & -0.06 \\
NDWI Mac & Range & $-0.19 ; 0.42$ & $-0.39 ; 0.11$ \\
Feeters & Mean and 95\% Cl & $0.12[0.11 ;$ & $-0.17[-0.18 ;$ \\
& & $0.14]$ & $-0.17]$ \\
& 25-50-75 percentiles & $0.03 ; 0.13 ; 0.25$ & $-0.21 ;-0.17 ;$ \\
& & & -0.14 \\
Elevation In & Range & $253 ; 292$ & $253 ; 292$ \\
meters & & & \\
& Mean and 95\% Cl & $266[266 ; 267]$ & $268[268 ; 269]$ \\
& 25-50-75 percentiles & $262 ; 265 ; 267$ & $261 ; 268 ; 274$ \\
\hline
\end{tabular}


Table 3 Environmental factors significantly associated with the presence of ponds in the 10 meter pixels

\begin{tabular}{|c|c|c|c|c|c|c|}
\hline \multirow[b]{3}{*}{ Number of obs. $=2460$} & \multicolumn{6}{|c|}{ Logistic regression } \\
\hline & \multicolumn{3}{|c|}{ Univariate ${ }^{* *}$} & \multicolumn{3}{|c|}{ Multivariate } \\
\hline & Coef. & $95 \% \mathrm{Cl}^{*}$ & p-value & Coef. & $95 \% \mathrm{Cl}^{*}$ & p-value \\
\hline \multicolumn{7}{|l|}{ NDTI } \\
\hline Per unit increase & -16.80 & $-18.91--14.69$ & $<0.0001$ & -38.81 & $-43.63--28.00$ & $<0.0001$ \\
\hline \multicolumn{7}{|l|}{ NDWI Mac Feeters } \\
\hline Per unit increase & 34.26 & $30.55-37.98$ & $<0.0001$ & 43.55 & $38.54-48.77$ & $<0.0001$ \\
\hline \multicolumn{7}{|l|}{ Elevation } \\
\hline Inferior to $270 \mathrm{~m}$ & 1 & & & 1 & & \\
\hline Superior or equal to $270 \mathrm{~m}$ & -1.03 & $-1.26--0.79$ & $<0.0001$ & -1.57 & $-2.22--0.92$ & $<0.0001$ \\
\hline
\end{tabular}

* 95\% confidence interval

** Only the variables significantly associated in the multivariate model

Logistic regression

\section{Step 2: Mapping of Anopheles larvae}

The Anopheles larvae presence/absence (164 observations positive for larvae and 3 negative) and the larval density were recorded during September-November 2009. A total of 16 ponds were digitized in the GIS. All the observations associated with those 16 collections were included in the analysis, for a total of 73 observations. Description of the distribution of the remotelysensed and meteorological variables used at this step is provided in Table 4. Results of the environmental and meteorological determinants of the Anopheles larval density recorded during the field work are presented in Table 5.

Those variables significantly associated with the larval density in multivariate analysis were the mean of the NDVI in and around the ponds and the current night Land Surface Temperature (night LST). The NDVI was negatively associated whereas the LST was positively associated with the Anopheles larval density in ponds.
The results of the likelihood ratio test $(p<0.001)$ showed that the random effect model was significantly different from a model fitted without accounting for the pond effect. Predictions of the larval densities for each observation allowed the calculation of Spearman correlation with the observed densities at 0.55 , showing medium correlation between the tested variables. Daily maps were drawn by inverting the global model predicting the Anopheles larval density for each water collection detected at step 1, for the full duration of the follow-up. Those maps were used as basis of step 3 .

\section{Step 3: Mapping of adult Anopheles}

During the study period, $99 \%$ of the Anopheles caught in the traps were Anopheles gambiae s.l. and 1\% Anopheles funestus. For both species, $89 \%$ of caught mosquitoes were female, $11 \%$ were male. The total larval production (surface water predicted in step 1 multiplied by the larval density predicted in step 2 for a given date) in the

Table 4 Description of the quantitative remotely-sensed and meteorological explicative variables associated with Anopheles larval densities in ponds

\begin{tabular}{|c|c|c|c|c|c|}
\hline Variable & & $\begin{array}{r}\text { Anopheles larval } \\
\text { density }^{*}<28\end{array}$ & $\begin{array}{r}\text { Anopheles larval density* } \\
>=28 \text { and }<47\end{array}$ & $\begin{array}{r}\text { Anopheles larval density* } \\
>=47 \text { and }<82\end{array}$ & $\begin{array}{l}\text { Anopheles larval } \\
\text { density }^{*}>=82\end{array}$ \\
\hline & $\begin{array}{l}n \\
\text { observations } \\
=73\end{array}$ & $n=17$ & $n=19$ & $n=18$ & $n=19$ \\
\hline \multirow{3}{*}{$\begin{array}{l}\text { NDVI (mean within pond + } \\
10 \mathrm{~m} \text { ring) }\end{array}$} & Range & $-0.02 ; 0.21$ & $-0.12 ; 0.30$ & $-0.12 ; 0.30$ & $-0.12 ; 0.30$ \\
\hline & $\begin{array}{l}\text { Mean and } \\
95 \% \mathrm{Cl}\end{array}$ & $0.07[0.04 ; 0.11]$ & $0.09[0.04 ; 0.14]$ & $0.04[-0.01 ; 0.10]$ & $0.01[-0.04 ; 0.05]$ \\
\hline & $\begin{array}{l}25-50-75 \\
\text { percentiles }\end{array}$ & $0.00 ; 0.05 ; 0.13$ & $0.00 ; 0.05 ; 0.21$ & $-0.01 ; 0.04 ; 0.05$ & $-0.05 ; 0.00 ; 0.05$ \\
\hline \multirow{3}{*}{$\begin{array}{l}\text { Night LST (weekly mean for } \\
\text { the survey area) In }{ }^{\circ} \mathrm{C}\end{array}$} & Range & $20.5 ; 23.1$ & $20.5 ; 23.1$ & $20.5 ; 23.1$ & $21.2 ; 23.1$ \\
\hline & $\begin{array}{l}\text { Mean and } \\
95 \% \mathrm{Cl}\end{array}$ & $21.4[21.0 ; 21.8]$ & $22.0[21.6 ; 22.4]$ & $21.9[21.5 ; 22.3]$ & $22.5[22.2 ; 22.7]$ \\
\hline & $\begin{array}{l}25-50-75 \\
\text { percentiles }\end{array}$ & $20.5 ; 21.1 ; 21.9$ & $21.1 ; 22.1 ; 22.6$ & $21.1 ; 21.9 ; 22.7$ & $21.9 ; 22.6 ; 23.0$ \\
\hline
\end{tabular}

\footnotetext{
* Larval density = number of larvae per sample (8 dips per pond per date). Categories were chosen following quantiles.
} 
Table 5 Meteorological and environmental factors associated significantly with Anopheles larval density in ponds

\begin{tabular}{|c|c|c|c|c|c|c|}
\hline \multirow[b]{3}{*}{ Number of obs. $=73$ Number of ponds $=16$} & \multicolumn{6}{|c|}{ Negative binomial regression with pond random effect } \\
\hline & \multicolumn{3}{|c|}{ Univariate ** } & \multicolumn{3}{|c|}{ Multivariate } \\
\hline & Coef. & $95 \% \mathrm{Cl} *$ & p-value & Coef. & $95 \% \mathrm{Cl} *$ & p-value \\
\hline $\begin{array}{l}\text { NDVI } \\
\text { (mean within pond + } 10 \text { m ring) } \\
\text { Per unit increase }\end{array}$ & -2.64 & $-4.93--0.34$ & 0.024 & -3.20 & $-5.36--1.03$ & 0.004 \\
\hline $\begin{array}{l}\text { Night LST } \\
\text { (weekly mean for the survey area) } \\
\text { Per }{ }^{\circ} \mathrm{C} \text { increase }\end{array}$ & 0.33 & $0.18-0.48$ & $<0.0001$ & 0.36 & $0.21-0.50$ & $<0.0001$ \\
\hline
\end{tabular}

* $95 \%$ confidence interval

** Only the variables significantly associated in the multivariate model

Negative binomial regression with pond random effect

buffers around the villages was not significantly associated with the number of Anopheles caught in the traps. None of the LULC classes extracted from the supervised classification was associated with the adult densities. Nevertheless, other environmental (NDPI) and meteorological (day LST and rainfall amount) factors were significantly associated with the adult densities (Tables 6 and 7). On the basis of the multivariate negative binomial regression, adult Anopheles predictions for the 10 study villages covered by the SPOT image were made for all capture dates between September $2^{\text {nd }}$ and October $23^{\text {rd }} 2009$. The comparison with actual values is presented in Figure 4. Figure 5 is the prediction map of Anopheles vector densities for October, $1^{\text {st }}, 2009$, for the 37 villages included in the SPOT-image outline.

\section{Discussion}

The present study allowed drawing predictive high-resolution risk maps for malaria vector abundance in a rural area following three modeling steps: the detection of water bodies, the larvae abundance in those water bodies and the adult Anopheles densities in villages. In the multivariate models for all three study steps, there was more than one relevant influencing factor for the presence of surface water as well as for Anopheles larvae and imagines. Due to the close interweavement of factors influencing the surface water presence and vector larvae and imagines abundance, the number of used and combined techniques is comparably higher than in studies that focus on a single step, e.g. detection of appropriate larval habitats or prediction of vector density.

Table 6 Description of the quantitative remotely-sensed and meteorological explicative variables associated with the adult Anopheles densities in villages

\begin{tabular}{|c|c|c|c|c|c|}
\hline Variable & & $\begin{array}{r}\text { Anopheles adult } \\
\text { density* }^{*}<110 \\
\end{array}$ & $\begin{array}{r}\text { Anopheles adult density } \\
>=110 \text { and }<145\end{array}$ & $\begin{array}{r}\text { Anopheles adult density } \\
>=145 \text { and }<240\end{array}$ & $\begin{array}{l}\text { Anopheles adult } \\
\text { density }>=240\end{array}$ \\
\hline & $\begin{array}{l}n \\
\text { observations } \\
=55\end{array}$ & $\mathrm{n}=12$ & $n=15$ & $n=14$ & $\mathrm{n}=14$ \\
\hline \multirow{3}{*}{$\begin{array}{l}\text { NDPI } \\
\text { (mean in } 500 \mathrm{~m} \text { buffer around } \\
\text { study villages) }\end{array}$} & Range & $0.06 ; 0.13$ & $0.06 ; 0.13$ & $0.06 ; 0.13$ & $0.06 ; 0.13$ \\
\hline & $\begin{array}{l}\text { Mean and } \\
95 \% \mathrm{Cl}\end{array}$ & $0.09[0.07 ; 0.10]$ & $0.08[0.08 ; 0.09]$ & $0.08[0.07 ; 0.09]$ & $0.09[0.08 ; 0.10]$ \\
\hline & $\begin{array}{l}25-50-75 \\
\text { percentiles }\end{array}$ & $0.07 ; 0.08 ; 0.09$ & $0.07 ; 0.09 ; 0.10$ & $0.07 ; 0.08 ; 0.08$ & $0.08 ; 0.09 ; 0.10$ \\
\hline \multirow{3}{*}{$\begin{array}{l}\text { Day LST(weekly mean for the } \\
\text { survey area) } \\
\ln { }^{\circ} \mathrm{C}\end{array}$} & Range & $27.0 ; 33.0$ & $26.2 ; 33.0$ & $23.1 ; 30.6$ & $23.1 ; 27.7$ \\
\hline & $\begin{array}{l}\text { Mean and } \\
95 \% \mathrm{Cl}\end{array}$ & $29.9[29.0 ; 30.9]$ & $29.6[28.8 ; 30.4]$ & $26.9[25.6 ; 28.2]$ & $24.5[23.8 ; 25.3]$ \\
\hline & $\begin{array}{l}25-50-75 \\
\text { percentiles }\end{array}$ & $29.5 ; 29.8 ; 30.4$ & $28.7 ; 30.0 ; 30.3$ & $24.4 ; 27.7 ; 28.7$ & $23.5 ; 23.8 ; 25.4$ \\
\hline \multirow{3}{*}{$\begin{array}{l}\text { Rainfall amount (sum during } 15 \\
\text { preceding days for each village) } \\
\text { In } \mathrm{mm}\end{array}$} & Range & $22.1 ; 92.0$ & $15.3 ; 147.4$ & $22.1 ; 168.4$ & $38.1 ; 220.2$ \\
\hline & $\begin{array}{l}\text { Mean and } \\
95 \% \mathrm{Cl}\end{array}$ & $55.2[39.6 ; 70.8]$ & $51.9[34.0 ; 69.7]$ & $91.2[64.3 ; 118.2]$ & $145.7[114.8 ; 176.6]$ \\
\hline & $\begin{array}{l}25-50-75 \\
\text { percentiles }\end{array}$ & 36.6; 46.5; 78.7 & $25.6 ; 38.1 ; 73.6$ & $41.2 ; 83.3 ; 131.2$ & $131.3 ; 148.8 ; 175.3$ \\
\hline
\end{tabular}


Table 7 Meteorological and environmental factors associated with adult Anopheles abundance in Nouna region in September-November 2009

\begin{tabular}{|c|c|c|c|c|c|c|}
\hline \multirow[b]{3}{*}{$\begin{array}{l}\text { Number of obs. }=55 \\
\text { (Nights withmosquito captures) Number of villages }=10\end{array}$} & \multicolumn{6}{|c|}{ Negative binomial regression with village random effect } \\
\hline & \multicolumn{3}{|c|}{ Univariate } & \multicolumn{3}{|c|}{ Multivariate } \\
\hline & Coef. & $95 \% \mathrm{Cl} *$ & p-value & Coef. & $95 \% \mathrm{Cl} *$ & p-value \\
\hline \multicolumn{7}{|l|}{$\begin{array}{l}\text { NDPI } \\
\text { (mean in } 500 \mathrm{~m} \text { buffer around study villages) }\end{array}$} \\
\hline Per unit increase & 6.01 & $-1.36-13.38$ & 0.110 & 7.52 & $0.77-14.27$ & 0.029 \\
\hline \multicolumn{7}{|l|}{$\begin{array}{l}\text { Day LST } \\
\text { (weekly mean for the survey area) }\end{array}$} \\
\hline Per ${ }^{\circ} \mathrm{C}$ increase & -0.16 & $-0.19--0.12$ & $<0.0001$ & -0.16 & $-0.20--0.12$ & $<0.0001$ \\
\hline \multicolumn{7}{|c|}{ Rainfall amount (sum during 15 preceding days for each village) } \\
\hline Per $10 \mathrm{~mm}$ increase & 0.06 & $0.04-0.08$ & $<0.0001$ & & & NS \\
\hline
\end{tabular}

* $95 \%$ confidence interval

Binomial negative regression with village random effect. Univariate and multivariate analysis

Step 1: Mapping of surface water

The digital elevation model turned out to be an indicator for surface water presence and swampy areas even in the survey region's setting with little differences in local altitudes, while from survey regions that are more heterogeneous and hilly this correlation and even its influence on malaria parasite prevalence has already been stated [37]. The NDWI Mac Feeters was positively correlated with the presence of water, in line with the fact that it is an indicator that increases with open

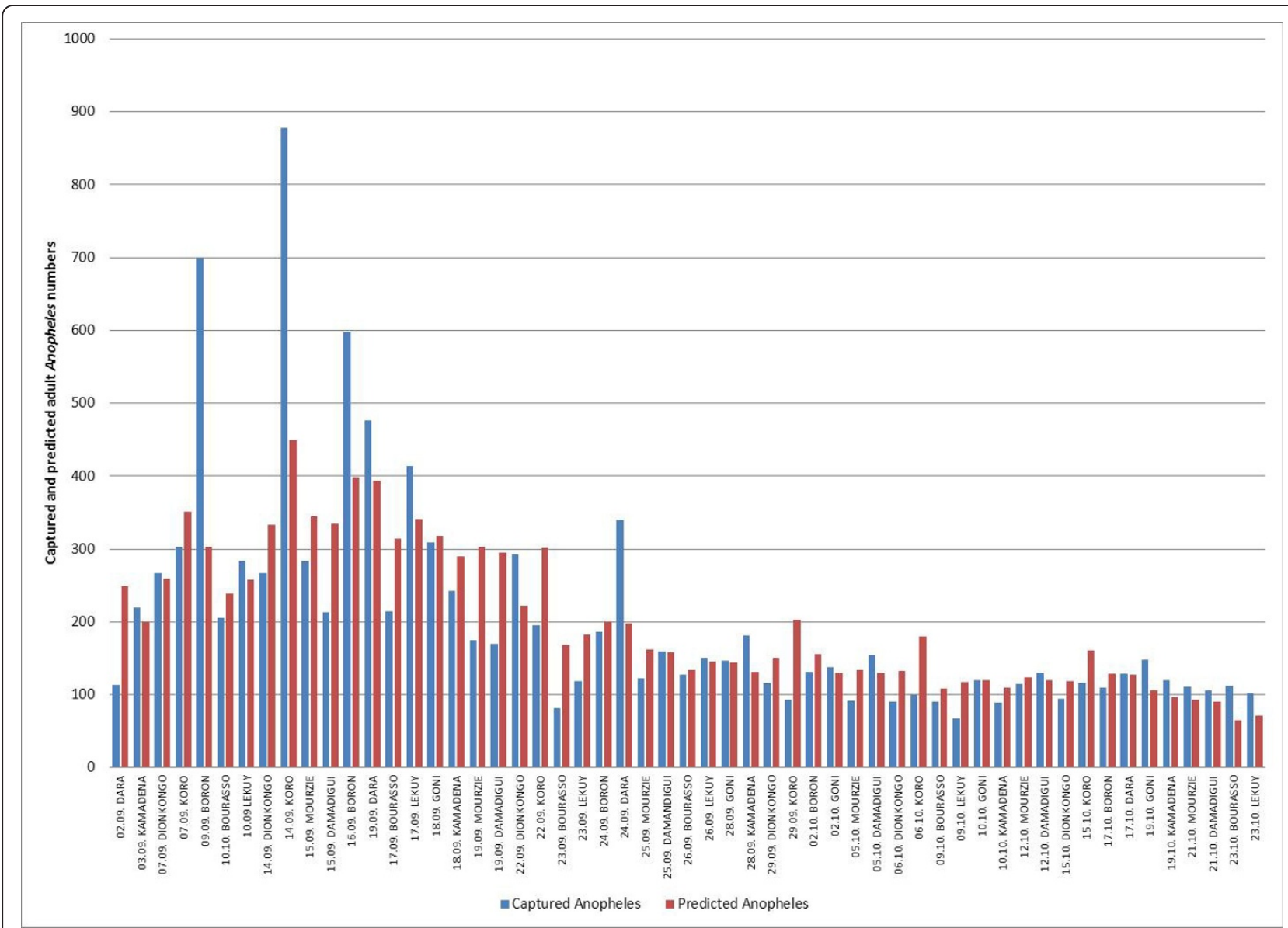

Figure 4 Captured (blue) and predicted (red) Anopheles numbers for 10 study villages with continuous larvae sampling and position of buffer zone within the satellite scene for the duration of mosquito captures (2nd September - 23 rd October 2009). 


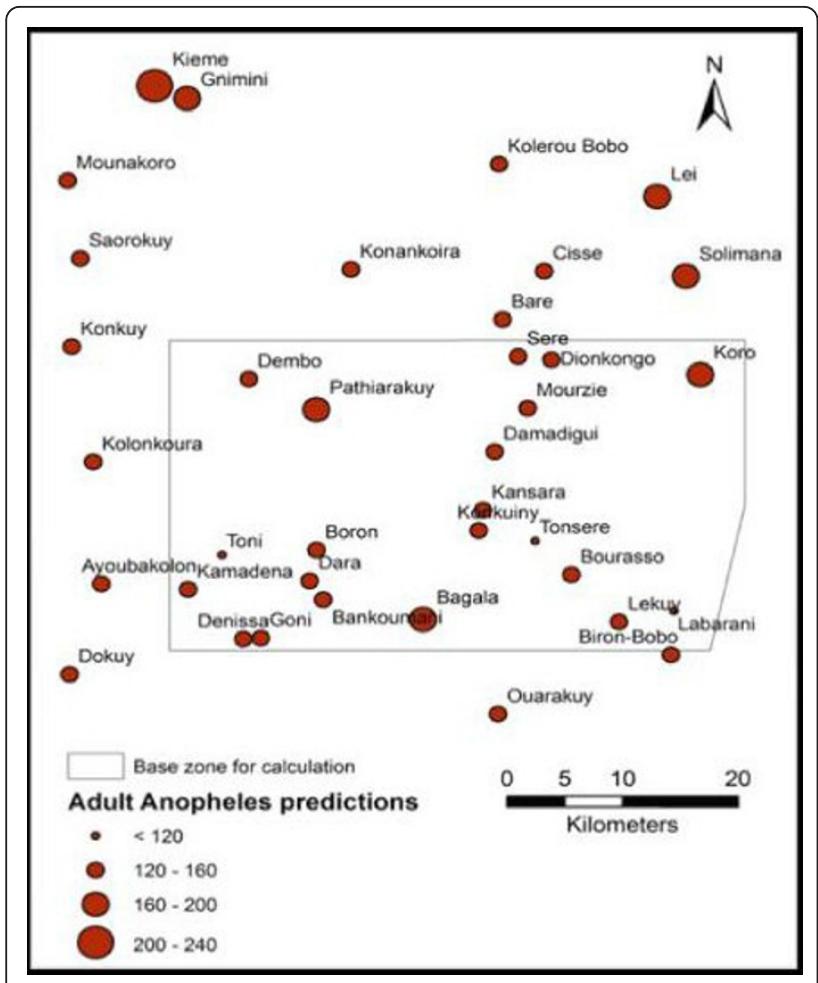

Figure 5 Adult Anopheles predictions for 37 villages within the satellite scene of SPOT 5 for the 1st October 2009. Data used for the predictions in all 40 villages have been derived from villages within the "base zone for calculations", the zone in which data was taken during fieldwork.

water presence, having been previously used for water detection [26,27]. The NDTI, initially designed to describe water turbidity, increases when water bodies become muddy and have spectral reflectance similar to bare soils [24] so it was logically negatively associated with the presence of water.

The smallest pond recorded on the ground covered one $10 \mathrm{~m}$ pixel so the direct water detection - using indices thresholds coupled with photointerpretation $[24,25]$ - was not appropriate. Indeed, it is commonly stated that object detection is feasible only when the object size is at least 1.5 times larger than the pixel size. Instead, statistical modelling allowed to benefit from several remotely sensed data sources that could be put together to predict the probability of presence of ponds. This methodology already proved to be efficient for detection of small Anopheles breeding sites in urban settings [27]. The pixels that were predicted as belonging to water bodies were grouped into water collections as single objects, as it has been done in the North of Senegal for the mapping of ponds harbouring larvae for Rift Valley Fever vectors $[24,25]$. Indeed, important predictors that could further be related to the presence of larvae, such as shade around the collection, were water body-related. In consequence, they had to be mapped at the level of the water collection and not at the pixellevel.

Step1 took advantage of the availability of a high resolution SPOT image that was acquired at the time of the field collections and that allowed to predict the presence of relatively small ponds recorded on the ground. As the image was taken during the rainy season, maximum water collections were predicted, that could further be weighted depending on the season. Even at $90 \mathrm{~m}$ spatial resolution, the DEM provided useful information for mapping the surface water and it should be expected that a DEM with an increased spatial resolution would improve the prediction by highlighting small altitude contrasts.

\section{Step 2: Mapping Anopheles larvae}

The findings were generally in line with the findings of other studies but show some particularities due to the very high resolution remote sensing approach. The NDVI at this scale turned out to be a hindering factor for larval production in contrast to most studies that utilize satellite imagery at a lower scale [38-40]. As far as the authors are aware, this correlation is unique to this study but may be reverse if changing towards a different scale. In the present study, the NDVI could have been a proxy of shade on the water collection or surface vegetation that are both usually related to lower Anopheles larval densities [41-43]. In consequence, the negative association between NDVI and the larval density was coherent with the biological mechanisms of larval development already highlighted in ground studies.

The night LST during the ground prospecting days was significantly positively related to the Anopheles larval densities in the water collections. In breeding sites, the entire development cycle from egg to the emerging imago can be completed under favorable conditions. This cycle's duration can vary between 1 and 3 weeks, depending on water and air temperatures, assuming sufficient food availability. Its length shortens with temperature increase [44] in accordance with the observation that LST was significantly positively associated with the density of larvae. Night LST showed stronger correlation than day temperature, probably due to the decreased impact of solar radiation and a more representative portrait of the average water temperature.

The cumulated rainfall during the 15 days preceding the day of larvae collection was positively associated with the low/high densities of larvae (results not shown) in univariate analysis. Rainfall patterns steer the availability of surface water for mosquito larvae breeding. In this study, only flooded water collections were included, so rainfall was already taken into account by definition. 
Nevertheless, the amount of rainfall could be a proxy for the persistence of water bodies, providing sufficient time for larvae to develop. On the other hand, rainfall might be a surrogate variable for global larval productivity within a region.

Step 2 benefited from the high spatial resolution of the SPOT image and the high temporal resolution of the meteorological data. Indeed, rainfall and temperature were taken into account at coarse spatial resolution (village and study area levels) which was consistent with scales of the meteorological heterogeneity. Nevertheless, the daily or weekly repetition of data was necessary for evaluating the evolutions of local conditions favourable for larvae development.

\section{Step 3: Mapping adult Anopheles}

The multivariate model predicting the Anopheles adult densities at the village level included an environmental and a meteorological variable, which allowed recording of a spatial (using NDPI in $500 \mathrm{~m}$ buffers around the villages) effect that differed between villages and a temporal effect (using weekly LST).

The NDPI was correlated with the number of captured mosquitoes. Increasing values for the NDPI characterize the presence of mixed pixels that show both, water and vegetation. The presence of this mixed environment can be seen as an ideal prerequisite for emerging imagines to rest. In consequence, the NDPI was logically associated positively with the Anopheles adult densities.

As a meteorological factor, night LST was not significantly associated with the adult mosquito density whereas day LST was negatively associated. The higher the day LST, the lower the number of mosquitoes caught, which may indicate higher environmental stress, making it more difficult to survive or search for blood meal. Higher day LSTs in this region also go hand-inhand with a lower relative humidity, especially during the rainy season. Lower environmental air humidity is less appropriate for mosquitoes survival [45] and blood meal retrieval success [46].

The cumulative amount of rainfall in the 15 preceding days was significantly positively correlated with the adult Anopheles density in univariate analysis. This is likely to be explained by the increased number and extended outlast of larval habitats. It can also be an indicator of humid air conditions that favors adult mosquito survival.

The prediction for larval densities in environmental habitats within the buffer zone around mosquito capture points $(500 \mathrm{~m})$ was not significantly correlated with the imagines abundance. In extrapolating the prediction models for water collections and larval densities to assess adult Anopheles densities, some errors were accepted, such as follows.

- Randomly created points for the absence of surface water did possibly fall to some extent into zones that were covered with water or had high soil humidity. In consequence, the map of water collection could have been biased. Here, a more detailed study of the situation around the study villages would be needed, with the collection of ground absence points (i.e. absence of water).

- The quality of the validation of the prediction of larval densities with actual ground values was moderate, larger field dataset collections may improve the accuracy of the models.

- Working with a single satellite image, the positions and in particular the dimensions of ponds and other surface water were static and did not take into consideration the possible change in circumference after rainfalls or longer periods of continuous evaporation. The acquisition of several images could improve this point, as well as the modeling of the size of the ponds depending on rainfall amount and distribution as it has been done in North Senegal [25].

- Step 2 was undertaken to model larval densities, as no multivariate model could have been adjusted to predict the presence/absence of larvae. In consequence, the water collections that were not breeding sites could have been misclassified.

\section{Ground entomological data}

The field work undertaken in the Nouna region in the 2009 rainy season showed that most of the Anopheles caught in traps were An. gambiae s.l. that are known to be vectors for malaria. In consequence, risk maps drawn in the present study, may be seen as basis information for malaria risk mapping as the location of the vector's larval habitats and their dynamics are the primary determinants of the spatial and temporal distribution of malaria transmission. Then, in addition to this entomological approach, it should be emphasized that malaria transmission occurs only if a competent infected vector meets a sensitive human population; if a Plasmodium reservoir is present.

Data was collected from September to November, the period representing the peak and outgoing rainy season. Onset of precipitations is volatile during the last years but usually starts in June. The adult vector abundance, and with some delay malaria transmission find their peak around September. In consequence, the risk predicted in the present study can be seen as the maximum annual entomological malaria risk. Even given the much 
lower malaria transmission during more than 6 months due to drastically reduction of environmental habitats and rainfall, an extended future study including more survey month could allow to better understand the year round vector dynamics. Still little is known about the vector resting places during dry season and the process of re-emergence in rainy season.

Only the ponds have been followed-up in and around the study villages while small water collections that are known to be seasonally productive breeding sites of $A n$. gambiae s.l. were not included for logistical reasons. It is argued that the larval productivity recorded at pond level may have been a surrogate evaluation of the total productivity in the villages. Nevertheless, it cannot be excluded that the lack of association between larval and adult densities may partly rely on this partial sampling. In addition, the use of light traps to catch adult mosquitoes may have biased the estimates of vector densities e.g. depending on the density [47] and have introduced noise that could also explain the absence of significant association between the larval and adult densities.

In general, differences in vector abundance between villages may not only be subject to environmental, but also anthropogenic variables. Within the study area, there were no vector control interventions performed during the study year and the use of bed nets was equally distributed. In consequence, no bias was introduced when evaluating entomological figures.

\section{Conclusion}

Remotely sensed environmental and meteorological data allowed the prediction of water presence in the region of Nouna, as well as the dynamic prediction of Anopheles larval and adult densities. While high resolution satellite data provided possibilities for spatial mapping of vector abundance, the amount and regional distribution of precipitations and the temperature are the drivers for vector development; the temporal component of the risk model. The results of the present study could be seen as the basic element of a dynamic system aiming at facilitating real-time monitoring of human health in rural Burkina Faso. The derived risk maps may keep validity for several years up to a decade, since the geographic factors change only within small limits. Having ground truth data on the region's characteristic environmental features, the extension of this approach to neighboring regions should be possible with a significantly reduced need for preparatory fieldwork. With the acquisition of additional satellite images and weather data, predictions on vector abundance for bordering areas can be performed. For usage in additional regions, the techniques appliance can be probably performed with drastically decreased costs due to the omission of extensive fieldwork components.

\section{Acknowledgements}

The SPOT-5 images are provided by the ISIS program from CNES. The project is supported by the French Minsitry of Ecology (MEDDTL) through its program GICC (Gestion et Impacts du Changement Climatique) We are deeply grateful to the people in the study villages for their cooperation and to the local staff of CRSN for their valuable work.

\section{Author details}

${ }^{1}$ Institute of Public Health, University of Heidelberg, Heidelberg, Germany. ${ }^{2}$ Observatoire Midi Pyrénées/Laboratoire d'Aérologie, Toulouse, France. ${ }^{3}$ Centre National d'Etudes Spatiales (CNES), Toulouse, France. ${ }^{4}$ Centre de Recherche en Santé de Nouna, Nouna, Burkina Faso. ${ }^{5}$ Centre for Global Health Research, Umeå University, Umeå, Sweden.

\section{Authors' contributions}

PD contributed to the conception and the design of the study, collected the field data and contributed to the analysis and interpretation of the data and to the writing of the paper. VM contributed to the study design, the analysis and interpretation of the data and wrote the paper. JPL contributed to the conception and the design of the study and the interpretation of the data. CV contributed to the analysis and interpretation of the data. AS contributed to the conception and the design of the study. RS contributed to the conception and the design of the study. All authors read and approved the final manuscript.

\section{Competing interests}

The authors have not received any funding or benefits from industry to conduct this study.

Received: 3 January 2012 Accepted: 23 March 2012

Published: 23 March 2012

\section{References}

1. Rogers DJ, Randolph SE, Snow RW, Hay SI: Satellite imagery in the study and forecast of malaria. Nature 2002, 415:710-715.

2. Machault V, Vignolles C, Borchi F, Vounatsou P, Pages F, Briolant S, et al: The use of remotely sensed environmental data in the study of malaria. Geospat Health 2011, 5:151-168.

3. Beck LR, Lobitz BM, Wood BL: Remote sensing and human health: new sensors and new opportunities. Emerg Infect Dis 2000, 6:217-227.

4. Craig MH, Snow RW, le Sueur D: A climate-based distribution model of malaria transmission in sub-Saharan Africa. Parasitol Today 1999, 15:105-111.

5. Snow RW, Craig MH, Deichmann U, le Sueur D: A preliminary continental risk map for malaria mortality among African children. Parasitol Today 1999, 15:99-104.

6. Ceccato P, Connor SJ, Jeanne I, Thomson MC: Application of geographical information systems and remote sensing technologies for assessing and monitoring malaria risk. Parassitologia 2005, 47:81-96.

7. Clarke KC, McLafferty SL, Tempalski BJ: On epidemiology and geographic information systems: a review and discussion of future directions. Emerg Infect Dis 1996, 2:85-92.

8. Diuk-Wasser MA, Bagayoko M, Sogoba N, Dolo G, Toure MB, Traore SF, et al: Mapping rice field anopheline breeding habitats in Mali, West Africa, using Landsat ETM + sensor data. Int J Remote Sens 2004, 25:359-376.

9. Hay SI, Snow RW, Rogers DJ: Predicting malaria seasons in Kenya using multitemporal meteorological satellite sensor data. Trans $R$ Soc Trop Med Hyg 1998, 92:12-20.

10. Thomas CJ, Lindsay SW: Local-scale variation in malaria infection amongst rural Gambian children estimated by satellite remote sensing. Trans R Soc Trop Med Hyg 2000, 94:159-163.

11. Beck LR, Rodriguez MH, Dister SW, Rodriguez AD, Rejmankova E, Ulloa A, et al: Remote-sensing as a landscape epidemiologic tool to identify villages at high-risk for malaria transmission. AmJTrop Med Hyg 1994, 51:271-280.

12. Beck LR, Rodriguez MH, Dister SW, Rodriguez AD, Washino RK, Roberts DR, et al: Assessment of a remote sensing-based model for predicting malaria transmission risk in villages of Chiapas, Mexico. AmJTrop Med Hyg 1997, 56:99-106.

13. Rejmankova E, Roberts DR, Pawley A, Manguin S, Polanco J: Predictions of adult anopheles-albimanus densities in villages based on distances to remotely-sensed larval habitats. AmJTrop Med Hyg 1995, 53:482-488. 
14. Roberts DR, Paris JF, Manguin S, Harbach RE, Woodruff R, Rejmankova E, et al: Predictions of malaria vector distribution in Belize based on multispectral satellite data. AmJTrop Med Hyg 1996, 54:304-308.

15. Adimi F, Soebiyanto RP, Safi N, Kiang R: Towards malaria risk prediction in Afghanistan using remote sensing. Malaria Journal 2010, 9:125-136.

16. Charoenpanyanet $A$, Chen $X$ : Satellite-based modeling of Anopheles mosquito densities on heterogeneous land cover in Western Thailand. The International Archives of the Photogrammetry, Remote Sensing and Spatial Information Sciences 2008, 37:159-164.

17. Briet OJT, Dossou-Yovo J, Akodo E, van de Giesen N, Teuscher TM: The relationship between Anopheles gambiae density and rice cultivation in the savannah zone and forest zone of Cote d'Ivoire. Trop Med Int Health 2003, 8:439-448.

18. Diuk-Wasser MA, Toure MB, Dolo G, Bagayoko M, Sogoba N, Sissoko I, et al: Effect of rice cultivation patterns on malaria vector abundance in ricegrowing villages in Mali. AmJTrop Med Hyg 2007, 76:869-874.

19. Robert V, Gazin P, Carnevale P: Malaria transmission in three sites surrounding the area of Bobo Dioulasso (Burkina Faso): The savanna, a rice field and the city. Bull Soc Vector Ecol 1987, 12:41-43.

20. Shuttle Radar Topography Mission. 2011 [http://www2.jpl.nasa.gov/srtm/]

21. Jarvis A, Reuter HI, Nelson A, Guevara E: Hole-Filled Seamless SRTM data V4. International Centre for Tropical Agriculture (CIAT); 2008.

22. Land Processes DAAC: MODIS Reprojection Tool User's Manual. 2011

23. Marechal F, Ribeiro N, Lafaye M, Guell A: Satellite imaging and vectorborne diseases: the approach of the French National Space Agency. Geospatial Health 2008, 3:1-5.

24. Lacaux JP, Tourre YM, Vignolles C, Ndione JA, Lafaye M: Classification of ponds from high-spatial resolution remote sensing: Application to Rift Valley Fever epidemics in Senegal. Remote Sens Environ 2006, 106:66-74.

25. Vignolles C, Lacaux JP, Tourre YM, Bigeard G, Ndione JA, Lafaye M: Rift Valley fever in a zone potentially occupied by Aedes vexans in Senegal: dynamics and risk mapping. Geospat Health 2009, 3:211-220.

26. Machault V, Gadiaga L, Vignolles C, Jarjaval F, Bouzid S, Sokhna C, et al: Highly focused anopheline breeding sites and malaria transmission in Dakar. Malaria Journal 2009, 8:138-159.

27. Machault V: Utilisation de données d'observation de la terre par satellite pour l'evaluation des densités vectorielles et de la transmission du paludisme. Marseille: Université de la méditerranée, Thèse de doctorat, Faculté de médecine de Marseille; 2010

28. Dambach P, Sie A, Lacaux JP, Vignolles C, Machault V, Sauerborn R: Using high spatial resolution remote sensing for risk mapping of malaria occurrence in the Nouna district, Burkina Faso. Glob Health Action 2009, 2, doi:10.3402/gha.v2i0.2094.

29. Rouse JW, Hass RH, Schell JA, Deering DW: Monitoring vegetation systems in the great plains with ERTS 1973, 309-317.

30. Huete AR: A soil-adjusted vegetation index (SAVI). Remote Sens Environ 1988, 25:295-309.

31. Gao B: NDWI - A normalized difference water index for remote sensing of vegetation liquid water from space. Remote Sens Environ 1996, 58:257-266.

32. MCFeeters SK: The use of the normalised difference water index (NDWI) in the delineation of open water features. Int J Remote Sens 1996 17:1425-1432.

33. Xu H: Modification of normalised difference water index (NDWI) to enhance open water features in remotely sensed imagery. Int $J$ Remote Sens 2006, 27:3015-3033.

34. Cho S-H, Lee H-W, Shin E-H, Lee H-I, Lee W-G, Kim C-H, et al: A markrelease-recapture experiment with Anopheles sinensis in the northern part of Gyeonggi-do, Korea. Kor J Parasitol 2002, 40:139-148.

35. Ejercito A, Urbino M: Flight range of gravid and newly emerged Anopheles. Bulletin of the World Health Organisation 1951, 4:663-671

36. Quraishi MS, Esghi N, Faghih MA: Flight range, lengths of gonotrophic cycles, and longevity of P-32-labeled Anopheles stephensi mysorensis. $J$ Econ Entomol 1966, 59:50-55.

37. Balls MJ, Bodker R, Thomas CJ, Kisinza W, Msangeni HA, Lindsay SW: Effect of topography on the risk of malaria infection in the Usambara Mountains, Tanzania. Trans R Soc Trop Med Hyg 2004, 98:400-408.

38. Rogers DJ: Satellite imagery, tsetse and trypanosomiasis in Africa. Prev Vet Med 1991, 11:201-220.
39. Thomson MC, Connor SJ: Environmental information systems for the control of arthropod vectors of disease. Med Vet Entomol 2000, 14:227-244.

40. Tourre YM, Jarlan L, Lacaux JP, Rotela CH, Lafaye M: Spatio-temporal variability of NDVI-precipitation over southernmost South America: possible linkages between climate signals and epidemics. Environmental Research Letters 2008, 3:1-9.

41. Gillies MT, Coetzee M: A supplement to the anophelinae of Africa south of the Sahara (Afrotropical region). Johannesburg: The South African Institute for Medical Research; 1987, 55.

42. Gimnig JE, Ombok M, Kamau L, Hawley WA: Characteristics of larval anopheline (Diptera: Culicidae) habitats in western Kenya. J Med Entomol 2001, 38:282-288.

43. Matthys B, N'Goran EK, Kone M, Koudou BG, Vounatsou P, Cisse G, et al: Urban agricultural land use and characterization of mosquito larval habitats in a medium-sized town of Cote d'Ivoire. J Vector Ecol 2006, 31:319-333.

44. Bayoh MN, Lindsay SW: Effect of temperature on the development of the aquatic stages of Anopheles gambiae sensu stricto (Diptera: Culicidae). Bull Entomol Res 2003, 93:375-381.

45. Pampana E: A Textbook of Malaria Eradication. London: Oxford Publishing; 1969.

46. Takken W, Dekker T, Wijnholds YG: Odor-mediated flight behavior of Anopheles gambiaeGiles Sensu Stricto and A-stephensiListon in response to CO2, acetone, and 1-octen-3-ol (Diptera: Culicidae). J Insect Behav 1997, 10:395-407.

47. Mbogo CN, Glass GE, Forster D, Kabiru EW, Githure Jl, Ouma JH, et al: Evaluation of light traps for sampling anopheline mosquitoes in Kilifi, Kenya. J Am Mosa Control Assoc 1993, 9:260-263.

doi:10.1186/1476-072X-11-8

Cite this article as: Dambach et al: Utilization of combined remote sensing techniques to detect environmental variables influencing malaria vector densities in rural West Africa. International Journal of Health Geographics 2012 11:8.

\section{Submit your next manuscript to BioMed Central and take full advantage of:}

- Convenient online submission

- Thorough peer review

- No space constraints or color figure charges

- Immediate publication on acceptance

- Inclusion in PubMed, CAS, Scopus and Google Scholar

- Research which is freely available for redistribution

Submit your manuscript at www.biomedcentral.com/submit
Ciomed Central 